\title{
Los agentes de la historia en los excursos sobre el pasado de Tucídides ${ }^{1}$
}

\section{The Agents of History in Thucydides' Excurses about the Past}

\author{
Laura Sancho Rocher ${ }^{2}$ \\ Universidad de Zaragoza (España)
}

Recibido: 01-11-16

Aprobado: 20-12-16

\section{Resumen}

Tucídides se propuso concentrar la mirada en la guerra que había vivido, evitando digresiones anecdóticas que distrajeran la atención del lector. No obstante, para entender las causas y el devenir de la guerra, se sintió obligado a indagar en el pasado, próximo y lejano. La labor de búsqueda de datos y el esfuerzo de reconstrucción e interpretación sobre el pasado dio lugar a los llamados excursos de la Historia de la guerra del Peloponeso. La profundidad temporal ofrecida al lector mediante los paréntesis discursivos contribuye a reforzar la noción medular de regularidad del comportamiento humano; los detalles de las digresiones, a la vez, ilustran las particularidades con las que la naturaleza humana se manifiesta. Así Tucídides pone de relieve que los recursos económicos y la flota, la unidad política y la cohesión en torno a un buen líder y, finalmente, las alianzas internacionales fueron factores más determinantes para el poder que las particularidades del sistema político o la filiación étnica. No obstante, Tucídides no olvida que el "carácter nacional" de

\footnotetext{
${ }^{1}$ Trabajo realizado en el marco del Proyecto HAR2015-63549-P (MINECO / FEDER). Todas las fechas del texto son antes de Cristo.

2 (1sancho@unizar.es) Catedrática de Historia Antigua de la Universidad de Zaragoza. Su investigación aborda diversas manifestaciones relativas a la democracia ateniense: el pensamiento político ("Kerdos, philia and mesoi: Aristotle and the Ways of Preventing stasis", Incidenza dell 'Antico 14, 2016, 143-174), la práctica política ("Temor, silencio y deliberación: La inhibición de la opinión en Tucídides", Gerión 33, 2015, 47-66.), así como los conflictos ideológicos ("Sociología de la stásis: I. El dêmos y los oligarcas en 411 a.C." y II. "El soporte social de los Treinta y el del dêmos en 404/3 a.C", Athenaeum 104, 2016, 5-30 y 373-396). Recientemente ha coordinado el volumen, $L a$ Antigüedad como paradigma: espejismos, mitos y silencios en el uso de la historia del mundo clásico por los modernos (Zaragoza, 2015).
} 
los principales contrincantes -vinculado a sus respectivas politeíai y paideíaihabía condicionado los comportamientos peculiares de ambos contendientes y, en suma, el curso concreto de la guerra.

Palabras-clave: excursos, poder, naturaleza humana, etnia, constitución política.

\begin{abstract}
When Thucydides decided to concentrate on the war he had lived, he preferred to avoid anecdotal digressions that would divert the reader's attention. However, in order to understand the origins and development of the war, he needed to investigate its recent and distant past. This effort to reconstruct and interpret the past explains the History of Peloponnesian War's excurses. These discursive parentheses avail the reader with temporal depth, thus strengthening the texts' key notion of regular human behavior. At the same time, the details provided by these digressions illustrate the particularities with which human nature manifests itself. So, by including these excurses, Thucydides lays bare to what extent economic resources and the fleet, political unity and cohesion around a good leader, and, lastly, international alliances were more decisive factors when it comes to power than the specific political system or the ethnic affiliation. However, he is aware that the main opponents' "national character" -linked to the their corresponding politeiai and paideiai- had a bearing on the peculiar behavior of both contenders and, all in all, on the course of the war.
\end{abstract}

Key-words: Excursus, Power, Human Nature, Ethnic Group, Political Constitution.

\title{
Introducción
}

La dificultad de investigar sobre tiempos remotos no escapaba al autor de la Historia de la guerra del Peloponeso. Tucídides, tal vez por eso, redactó una historia ceñida a un tema reciente y con una línea discursiva concreta y muy estricta. Una historia que, además, presenció y vivió de adulto $(1.1 ; 5.26 .1 ; 5)$. Sin embargo, en algunas circunstancias, como su antecesor, se torna en parte disperso y herodoteo (Canfora, 1982), y relata momentos del pasado -ora extensos, alejados y generales, ora breves, próximos y concretos- que lo distancian aparentemente de los temas de la guerra presente y, en parte, de la dinámica del poder. Se tratará en estas páginas de reflexionar sobre el interés que esos pasajes -a los que acostumbramos denominar excursos o digresiones- puede tener 
para la presentación y comprensión de la guerra que escribe Tucídides, y para deslindar los factores relativos a la humana naturaleza y a la organización cívica de los contendientes, agentes que, además, son los nexos clave en la concepción tucidídea del acontecer.

Explicar y no solo narrar es el objetivo de los historiadores, por eso la ordenación cronológica y los vínculos causales cobran en la historia un relieve que no poseen en otros géneros que se habían ocupado del pasado. Los historiadores aplicaban formas racionales de argumentación (analogía, inducción, valoración de testimonios) a cualquier noticia próxima o mítica. Heródoto, como es sabido, era amigo de confrontar versiones e informantes diversos e, incluso, frecuentemente gustaba mostrar por cuál se decantaba y las razones que lo movían a ello. Tucídides suele presentar una redacción aparentemente más acabada, razón que daba pie a que, hasta hace unas décadas, fuera frecuente considerarlo un científico objetivo ${ }^{3}$ y positivista. La tendencia inaugurada por Francis Cornford (Thucydides Mythistoricus, 1907), quien atinadamente puso de relieve la parte emocional y trágica de Tucídides, ha desencadenado un giro completo en la consideración del historiador ateniense. Hasta el extremo de que, recientemente, desde los años 70 del siglo XX, la valoración que a veces se hace de Tucídides como científico haya ido adquiriendo tintes negativos (Connor 1977), pues predomina la corriente que lo describe como mero retórico e incluso como impostor ${ }^{4}$, capaz de construir un relato (story), no más fiel a los hechos que otros, pero sí con mayor apariencia de objetividad. Si aceptáramos que Tucídides pretendía forjar una realidad virtual sin fisuras, carecería de sentido que los excursos fueran una distracción de ese propósito. No debemos dudar a priori de la honradez intelectual de Tucídides, aunque eso no excluya admitir que, como todo historiador, elaboró su material -selección de hechos y términos- para ofrecer la interpretación que creyó correcta.

Nadie enfatizó como Tucídides cuán ardua había sido su tarea. Sin duda así lo fue también en la evaluación de los hechos más alejados (1.21.1). Afirma que ha reconstruido en líneas generales cómo sucedieron las cosas en el pasado

3 Para de Romilly 1967: 12-13, 84-89, Tucídides, que se borra como individuo, deja hablar a los hechos; el resultado es que su historia reviste el aire de evidencia; en 1990: 10 califica su interpretación de honesta y reflexiva. Connor 1984: 16-17 opina que el historiador conoce bien las técnicas de persuasión (elección de episodios, diseño de eventos, elección de términos) pero evita los juicios explícitos de manera que la objetividad es, más que un fin en sí, parte de su técnica.

4 Para Hunter 1980: 194, 198 Tucídides aplica al pasado y a la lectura de sus fuentes una teoría preconcebida. En 1982: 32, basándose en de Romilly 1967: 242, escribe que es el conocimiento del presente lo que le haría inferir la reconstrucción del pasado. Por el contrario, si se tiene en cuenta lo abigarrado de la tradición mítica que elabora en sus excursos, se concluirá que el trabajo tucidídideo es más complejo de lo que Hunter cree. Un enfoque más equilibrado sobre la forma en que Tucídides escribe la Historia es el que da Gribble 1998. El historiador no impondría las interpretaciones sino que proporciona los mimbres para la reflexión. Tucídides presta voz a pensamientos diversos e interviene como narrador (más que como autor) para penetrar en la motivaciones individuales. 
remoto a través de los controvertidos indicios de sus fuentes $(1.20 .1 ; 21.1)$. A su trabajo de conjunto lo considera akribés $(22.2 ; 4 ; 6.54 .1)$, "exacto"5, tal vez por carecer de adorno y no tener por objetivo el entretenimiento, tò mythôdes (1.22.4; cf. 21.1) , y porque está sometido a comprobación (1.22.2

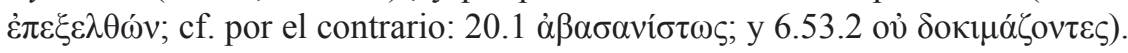
Pero no porque sus fuentes fueran mejores que las de otros -Tucídides trabaja con las mismas fuentes orales y poéticas-, sino por su capacidad y empeño para interpretarlas (5.26.5; cf. Gehrke 1993: 9-12). La cocina del historiador se percibe, mejor que en ningún lugar, en los excursos sobre el pasado, debido al uso frecuente de la primera persona y a la mención de la tradición (akoé), los indicios (semeîa) y las pruebas (tekméria). Tucídides, en contra de lo que actualmente muchos todavía repiten, no pretende ocultar su impronta e, incluso, dos veces recuerda al lector su papel de escritor o historiador (1.1.1 y 5.26.1). Hoy día puede resultar ingenua, o parecer soberbia, su convicción de haber hecho una reconstrucción verdadera (cf. 20.3; 21.1; 23.6), y de dejarnos una adquisición definitiva, pero eso no debería traducirse en que estaba más preocupado por embaucar hábilmente que por arrojar algo de luz sobre los acontecimientos (cf. Dover 1988; Gehrke 1993: 18-19; Gribble 1998, Raaflaub 2013).

Partiendo de la convicción de que Tucídides se propuso analizar los acontecimientos recientes con fines científicos, mi intención en estas páginas es interpretar los excursos como parte integral de su proyecto histórico. Como cualquier historiador, Tucídides, al decidir su objeto de estudio, y con el ánimo de contribuir a la mejor comprensión del mismo, se sintió motivado para salir del restringido marco temporal de la guerra e identificar, en otros momentos cronológicos, tanto los paralelismos con el presente como ciertas constantes universales, y esas reflexiones dieron pie a recorridos selectivos por el pasado donde destacó los factores explicativos que serían esenciales en su concepción de la historia. Seguramente, en ese ir y venir entre el pasado y el presente, se iría perfilando su personal visión de la naturaleza humana y de tò anthrópinon $(1.22 .4)^{7}$. Asimismo, descubrió que las maneras de actuar de cada una de las

\footnotetext{
${ }^{5}$ Concepto tomado del mundo de las profesiones (téchnai), especialmente la medicina científica. Está relacionado con la pretensión de precisión científica, radicada en testimonios e indicios, y con el seguimiento estricto de un método. Cf. Kurz 1970: 12; Trédé 1983.

${ }^{6}$ Para Flory 1990: 198-9 este concepto abarca lo que resulta agradable de oír pero está alejado de la verdad. Fowler 1996: 77 cree que, con la alusión a logógrafos o poetas, Tucídides no censura a Heródoto, sino a charlatanes del tipo de Hipias; Rood 2006: 235-236 sospecha más bien que es una insinuación de censura hacia la retórica forense. Ober 1998: 55 y n. 7 piensa en historiadores y oradores.

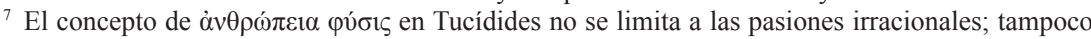
hay nada absolutamente necesario en la naturaleza humana, cf. Müri 1947 y Johnson 1993: 3-71. Para Stahl 1966, en la naturaleza humana sí predomina el elemento irracional, lo que, junto al azar, hace

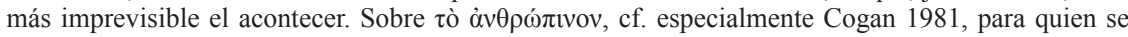
trata del proceso de deliberación que precede toda acción y que pone en juego ideas, sentimientos, emociones e ideologías.
} 
dos grandes ciudades rivales -y de sus respectivos dirigentes- mantenían homogeneidades y regularidades, y encontró una explicación para ello en la organización sociopolítica. De ahí nacería la idea de la constancia del carácter nacional, y de la gran influencia que los trópoi particulares, respectivamente, de atenienses y espartanos, originados en el pasado y en los nómoi de cada una de esas ciudades, había tenido en la marcha y desenlace de la guerra.

\section{El poder naval, los recursos económicos y la división de Grecia}

La Arqueología del libro I está colocada -lo que no es baladí- entre la presentación del autor y su obra (1.1) y los denominados capítulos metodológicos (1.20-23). Sirve para subrayar la envergadura de la tarea del redactor y la del episodio que investiga; pero también es la presentación de algunos de los factores históricos (recursos/poder/flota, unidad/división) que van a ser objeto de elaboración con la metodología que luego se explicita. Tucídides afirma haberse puesto a la tarea tan pronto como la guerra se declaró ${ }^{8}$, porque se habría dado cuenta de la importancia que iba a tener el conflicto, ya que las dos potencias enfrentadas habían reunido medios hasta entonces inimaginables, y porque el resto de los griegos se dividía respaldando respectivamente a atenienses y lacedemonios. No se trata de que la presente guerra sea vista aquí como el efecto de la riqueza acumulada, sino que el historiador sostiene que es más grande si aquella también lo es, y si los que se suman a las partes son más numerosos; y en este caso eran todos los griegos los divididos en dos bandos. El tema de

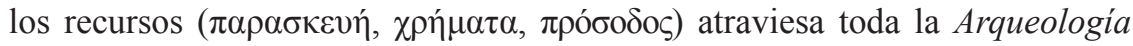
y está vinculado al del "progreso" "que acaba con la inestabilidad primitiva y el peligro de la piratería. No es omnipresente el asunto de la guerra en tanto que choque de dos grandes potencias, aunque sí es apuntado en el caso de la guerra de Troya y en el de las guerras médicas; pero estos dos acontecimientos no son presentados como epílogo inevitable del poderío acrecentado de cada

\footnotetext{
${ }^{8}$ Sin entrar en la tradicional polémica entre analíticos y unitaristas, lo decisivo es que, en su conjunto, toda la redacción está presidida por las mismas líneas clave. Tsakmakis 1995: 28-9 opina que Tucídides empezó a escribir una vez finalizada la guerra. Este extremo, lógicamente, explicaría mejor la coherencia interna de la obra. Por el contrario, Hornblower, basándose en el mismo participio $\grave{\alpha} \rho \xi \alpha ́ \alpha \varepsilon v o \zeta$ concluye que empezó a escribir eventos “que estaban en el futuro" (1991: 5-6). Rood 1998: 53-54 basa su interpretación unitaria en la cohesión temática, pero no excluye que la redacción no haya sido continua. Canfora 2016 también cree que escribió a lo largo de la guerra, y que dejó partes esbozadas que completó Jenofonte.

${ }^{9}$ No parece discutible que detrás del planteamiento de la Arqueología esté el sustrato de la literatura contemporánea sobre el progreso, pero la Arqueología no es un texto sobre el progreso sino una exposición de las circunstancias que potencian la hegemonía militar y el poder político. De Romilly 1966: 175-176, 182 argumenta que Tucídides no cree en el progreso moral y concibe la evolución histórica como sometida al azar y a la necesidad. Para la helenista gala, en Tucídides el tiempo es cíclico. Thomas 2011: 238 sostiene incluso que, frente a las contemporáneas teorías abstractas sobre el progreso, Tucídides opone las evidencias de la anomia moral (la epidemia, la stásis).
} 
parte, sino que en ellos se subraya que fueron empresas comunes de todos los griegos. Lo que la primera Arqueología transmite al lector es que, cuando la presente guerra se produjo, Grecia ya había superado muchas etapas históricas partiendo de unos orígenes tan humildes que son caracterizados por constantes migraciones debidas a la pobreza ${ }^{10}$, dispersión de la población, ausencia de fortificaciones y de comercio, e inexistencia de la conciencia de identidad helena $(1.2 .2 ; 3.3)^{11}$. La unión de los griegos, que es valorada positivamente por el historiador, requirió, en los momentos en que fue posible, de un líder; y la jefatura recaía cada vez en la ciudad que en esos momentos era considerada la más poderosa en riquezas económicas y/o demográficas.

La posesión de navíos, sin duda, denota la existencia de recursos previos pero, a su vez, origina más riqueza y poder sobre otros (1.15.1; cf. Gehrke 1993: 1-17). Minos (1.4.1) era poderoso y fue el primero en establecer una talasocracia; Agamenón (9.1), gracias a las riquezas heredadas de Pélope, poseía en su momento más naves que los otros griegos que, conscientes y temerosos de su poder, se pusieron a sus órdenes; y los tiranos -Polícrates de $\operatorname{Samos}^{12}$ o los tiranos de Sicilia ${ }^{13}$-, ya en época posterior a la guerra de Troya y las migraciones dorias, construyeron barcos, y también los tuvieron las ciudades de Corinto y Corcira (1.13-14.2). En esa época se fabricaban ya trirremes, pero advierte Tucídides que las flotas aún eran de poca envergadura y no siempre constituidas por naves modernas y homogéneas (1.14.1). Finalmente hace su aparición la armada de Atenas, construida inicialmente a propuesta de Temístocles, para preparar tanto el enfrentamiento con Egina como la previsible campaña de Jerjes (1.14.3). Parece lógico concluir que la prehistoria naval o marítima de Grecia estaba destinada a conducirnos a ese momento de máximo desarrollo (cf. de Romilly 1967: 285). Nada dice Tucídides, por otra parte, de los sistemas políticos - ni de su relación con el desarrollo de las flotas- hasta que anuncia el surgimiento de tiranías (1.13.1). Pero, si la escuadra es tan importante, alguna fortaleza debe de poseer también el régimen político ya que Esparta $(1.18 .1 ; 122.3)$ es presentada como la ciudad que combatió con éxito las tiranías (cf. Hdt. 5.92.1-2) gracias a su eunomía antigua, traída ya por los primeros dorios. Su poderío era terrestre -una fuente de poder militar tenida, en la Arqueología, por inferior a la marítima (1.15.2-3)-, pero le aseguró el papel de líder en la campaña contra el Medo en 480.

\footnotetext{
${ }^{10}$ En el caso ateniense, es la pobreza de la tierra la que libra al Ática de continuos vaivenes de población. Se trata de una explicación racional del mito nacional sobre la remota ocupación de la región por los atenienses, cf. Rosivach 1987: 302.

11 Cf. Gomme 1971: 94-98 para un contraste entre las concepciones de Tucídides y Heródoto relativas a la helenización de Grecia; en concreto, de los pelasgos y jonios por los dorios.

12 Heródoto (3.122.2) excluía al mítico Minos y hacía de Polícrates el fundador de la primera talasocracia histórica.

13 Luraghi 1995: 49-50 argumenta que la expresión tan genérica "los tiranos de Sicilia" en la Arqueología correspondería a la flota de Gelón quien, según Heródoto (7.158.4; 168.4), habría llegado a tener 200 trirremes.
} 
Las pesquisas de Tucídides a través de documentación dispersa conducían a comparar la guerra de finales del s. V -y la talasocracia que la precede- con las habidas anteriormente y a subrayar la eficacia de centralizar recursos. Mientras subrayaba los esfuerzos comunes de los poderes navales, apenas encontró indicios sobre la organización política, por tanto no relacionó necesariamente afianzamiento de un gran poder con sistema político. Se limitó a constatar que las basileíai primitivas fueron sustituidas por las tiranías cuando Grecia se hizo más próspera ${ }^{14}$. La Arqueología deja las cosas justo en el momento en el que se inicia la presente guerra. Tras haberse enfrentado juntos a los medos bajo la dirección espartana (1.18.2), dice nuestro historiador, se constituyeron dos coaliciones. Es decir, ya no predominaba la unión de muchos contra un enemigo externo, como en el caso de las guerras médicas, pero sí se afirmaron dos alianzas que incluían a todos los griegos; y eso caracteriza a la historia contemporánea. En la liga del Peloponeso, Esparta mantenía la hegemonía gracias al sistema político oligárquico, mientras que, en la alianza naval formada en torno de Atenas, lo que aseguraba el poder al hegemón era la concentración de los barcos en manos de Atenas, al sustituir por tributos los navíos que previamente poseyeron otras póleis (19; cf. 96.1; 99.3). Es un contraste extraño: Tucídides no concede demasiada importancia al sistema democrático como aglutinante de la confederación naval y sí a la reunión de recursos en manos del poder hegemónico. Resulta significativo que la Arqueología se cierre en el mismo punto prácticamente que la Pentecontecia, cuando solo Quíos y Lesbos permanecían como aliadas navales. Por tanto, cuando ya se había producido la rebelión y guerra de Samos (441), acontecimiento que sella el akmé del poder de Atenas y, por eso, es elegido para poner punto final a la digresión (Wecowski 2013).

La Pentecontecia se inscribe entre la asamblea de los espartiatas y la reunión de los aliados peloponesios - ambas celebradas en Esparta-; y tras dos discursos, uno corintio y otro ateniense, que introducen dos lecturas contrapuestas sobre el modo en el que el imperio ateniense se había consolidado. La Pentecontecia es la voz del historiador, y en estos capítulos dice haber logrado la exactitud que Helánico no alcanzó (1.97.2; cf. Hornblower 1991: 147-148). Él es quien elige los hitos más significativos ${ }^{15} \mathrm{y}$ enfatiza las respectivas dinámicas

14 Hornblower 1991: 42 califica de extraño en Tucídides el análisis sobre la evolución de las realezas primitivas hacia las tiranías.

15 Son muchos los silencios de Tucídides en la Pentecontecia, paréntesis que no busca decirlo todo acerca de los cincuenta años transcurridos, sino desplegar ante los ojos del lector qué es lo que resume la expresión "la causa más verdadera", cf. Stadter 1993: 42. Hornblower 1991: 179-182, 187 indica que el excurso se ocupa poco de la guerra contra los bárbaros, aunque en la Historia habría detalles que presupondrían la existencia de un acuerdo con los persas -la paz de Calias-; menciona también el silencio sobre la Guerra Sagrada de los años 450, y el de la fundación de Turios. Stadter 1993: 6668, enumera entre otros muchos silencios: el Decreto del Congreso, las medidas imperiales y todos los acontecimientos entre la guerra de Samos y la de Corcira. Tsakmakis 1995:87 añade la elipsis de Pericles en los asuntos de la culminación de los Largos Muros, del traslado del Tesoro o de la política de creación de cleruquías.

Araucaria. Revista Iberoamericana de Filosofía, Política y Humanidades, año 19, n 37. Primer semestre de 2017. Pp. 235-256. ISSN 1575-6823 e-ISSN 2340-2199 doi: 10.12795/araucaria.2017.i37.12 
que han marcado a lo largo de cinco décadas las relaciones entre Atenas y Esparta. La Pentecontecia es necesaria porque los aliados, los enemigos o los propios atenienses aluden una y otra vez a las batallas contra el Medo, a los hechos fundacionales de la alianza naval, y a la significación y evolución de la misma (cf. Rood 1999). Los corintios, aliados de los lacedemonios, pero muy críticos con ellos, responsabilizan de la situación de riesgo en la que se encontraría toda Grecia a los غ̇ंı $\rceil \delta \varepsilon v ́ \mu \alpha \tau \alpha(1.71 .2)$ anticuados de sus amigos

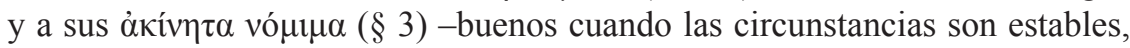
pero incapaces de ayudar a afrontar coyunturas variables-. La tendencia a la inacción de los lacedemonios es un rasgo del carácter nacional vinculado con su sistema social y político. También culpan a los lacedemonios de haber permitido que los atenienses elevaran sus murallas justo tras la retirada de Jerjes (69.1) y, con ello, de haber activado la sustitución hegemónica fuente del poderío de la ciudad rival. El alegato de los atenienses opta aparentemente por la paz aunque, para ello, los oradores proyecten la imagen de la ciudad -la propia del discurso patriótico para consumo interno- como salvadora de Grecia y merecedora de preeminencia y poder; una ciudad tal que el mero recuerdo de sus proezas pasadas debería frenar la belicosidad de los enemigos. Decir a los lacedemonios que ellos solos vencieron a los persas en Maratón (73.4; cf. en contra: [D.] 59.94), o que en Salamina fueron el arrojo, la táctica y la dirección ${ }^{16}$ atenienses los responsables de la victoria (74.1-2), es una medio verdad dirigida, en concreto, a la sensibilidad y mala conciencia de los lacedemonios. Los atenienses destacan la generosidad de su resolución de aquellos momentos y, finalmente, recuerdan a los oyentes que, si Atenas se hizo con la hegemonía, fue debido a que los lacedemonios prefirieron regresar a casa y no proseguir la guerra contra el Medo (cf. los mitileneos en 427 a.C., Th. 3.10.2). Las contrapuestas formas de reaccionar ante retos similares, que son propias de ambas comunidades, están vinculadas a regímenes políticos y formaciones militares diferentes. El poderío basado en la flota, en la que los thêtes son remeros, exige mayor arrojo y gasto, pero reporta también más gloria y poder. La Liga del Peloponeso era, por el contrario, una máquina de guerra hoplítica, y los espartiatas no podían cambiar ese modelo sin hacer peligrar el delicado equilibrio social interno. No sería extraño que Tucídides compartiera la idea que Aristóteles expresa en la Política (1274a 12-15) según la cual es el desarrollo de la flota el que acelera la evolución hacia la democracia plena. Lo que para él y sus contemporáneos sería una evidencia -que flota y democracia iban de la mano y en ese orden- no requeriría ser explicitado.

${ }^{16}$ Es una alusión a Temístocles como estratega de la batalla de Salamina, a quien los mismos espartanos honraron por ello; cf. Hdt. 8.124.2-3; Th. 1.74.4. Cf. Grethlein 2011: 257-260 para el uso interesado de los exempla históricos. 
Con la Pentecontecia Tucídides colocaba al lector en situación de juzgar el contenido y la intención de los discursos pronunciados por ambas partes antes de la declaración de guerra ${ }^{17}$, entre los cuales los mencionados constituyen un buen ejemplo. Y no solo los discursos previos, sino también otros que habían podido oírse en diferentes ambientes y circunstancias, y que siempre remitían a cómo habían de ser interpretadas las intenciones atenienses. Un ejemplo significativo lo constituye, en 415, la escena de la asamblea en Camarina, cuando el ateniense Eufemo, que pretendía persuadir a potenciales socios de las diferencias entre los aliados del Egeo y los de Sicilia, reconoció que en 479, tras una valerosa actuación contra el Persa, el objetivo ateniense fue librarse de la hegemonía que en Grecia tradicionalmente ejercían los lacedemonios (6.82.2), y argumentó que el sometimiento de los jonios a su mando fue justo porque estos pueblos habían ayudado al bárbaro en la invasión persa (§3). Las circunstancias del auditorio dorio aconsejaban no invocar el parentesco jonio, ni evocar la libertad con la que los jonios se habían unido a la alianza. Y, como Atenas solo perseguía ahora su seguridad, coincidente con la de Camarina, tampoco era momento de alegar generosidad.

En resumen la Pentecontecia se encuentra más allá de los argumentos de unos y otros; su función es ordenar hechos y darles una significación neutral y ajustada. El mensaje del historiador coincide con el de Eufemo solo en que Atenas persiguió su interés frente a Esparta desde el minuto cero, pero Tucídides no esconde que la alianza naval nació también gracias a la no disposición lacedemonia para seguir la guerra contra el Medo y al empuje y voluntad de los jonios. Tucídides, a diferencia de Eufemo, no hace reproche alguno a los griegos de Asia. La tarea del historiador se distancia de lo que es habitual entre oradores y, por tanto, de lo que de oídas conoce la mayoría. No es extraño que el discurso fúnebre que Tucídides pone en boca de Pericles en 431/0 prescinda de narrar el pasado, especialmente el imperial, algo que tendría que haber hecho según pautas consonantes con la ocasión y, en esa medida, podría haber empañado la imagen de ponderación del gran líder.

La digresión está dividida en dos partes (1.89-95; 98-118) muy bien diferenciadas por el tempo y detalle del propio relato (Gomme 1971: 363; Stadter 1993: 47; Tsakmakis 1995: 72; 78-79); en la primera leemos cómo los lacedemonios abandonaron la dirección de las acciones bélicas (89.2; y especialmente 95), mientras los atenienses reconstruían aceleradamente sus murallas siguiendo el consejo de Temístocles y este hacía su orgullosa aparición ante los espartanos (90-91). Todo este proceso es más un exponente de lo inestable de la reciente alianza de atenienses y lacedemonios que un reflejo

${ }_{17}$ Rood 2006: 239-242 asume que Tucídides dirige la interpretación de sus lectores, pero también reconoce que deja que el lector se implique y valore los argumentos enfrentados que él le presenta a través de antilogías.

Araucaria. Revista Iberoamericana de Filosofía, Política y Humanidades, año 19, n 37. Primer semestre de 2017. Pp. 235-256. ISSN 1575-6823 e-ISSN 2340-2199 doi: 10.12795/araucaria.2017.i37.12 
del temor a un eventual regreso de los persas (cf. 92.1). Al mismo tiempo, a instancias del gran héroe de Salamina, retomaron los atenienses las tareas del puerto (92.2) y, al seguir las indicaciones de Temístocles de "dedicarse al mar", parece claro que Tucídides quiere evidenciar cómo despertó la ambición hegemónica de Atenas. Con este planteamiento, en buena medida psicológico, se cierra la primera parte que es mucho más circunstanciada y narrativa que la segunda, y que deja patente el sesgo de las exposiciones que antes hemos resumido, así como la conveniencia de aplicar criterios correctos para interpretar todos los discursos con el fin de descartar los argumentos claramente tendenciosos, y así alcanzar una visión más verdadera. Tras relatar cómo los jonios rechazaron a Pausanias y a Dorcis, y el modo en que Atenas organizó la nueva alianza, el capítulo 97 es, en la práctica, una recapitulación a priori sobre la continua e inexorable evolución de la nueva liga naval $(\$ 1)$, y la enunciación que en primera persona hace el autor de qué es "esta digresión” ( $\S 2)$ : no otra cosa que una explicación de cómo se estableció el imperio de los atenienses y, en suma, el despliegue de la alethestáte próphasis (1.23.6). A partir de este momento, el lector ya no encuentra detalladas escenas dramáticas o apuntes psicológicos, ni iniciativas concretas de personajes relevantes. Ha de sobreentenderlos. Las acciones son siempre presentadas como emanando de los atenienses, de sus aliados rebeldes, o de sus enemigos; el páthos se alcanza a través de la misma sobriedad en la exposición de los acontecimientos (no se presenta deliberación alguna), de la regularidad de los comportamientos, y de la aparente distancia del relator; y todo ello conduce al lector a la conclusión de que el éxito ateniense era fruto de cierta osadía y de la incapacidad de reacción lacedemonia (cf. Tsakmakis 1995: 92-96). El intérprete actual sospecha una relación entre flota, imperio y democracia, pero Tucídides se limita a remarcar la inicial voluntad de poder mostrada por Temístocles y secundada por los atenienses.

Ya en 479 señala el propio historiador que los aliados del Peloponeso temían las consecuencias de que los atenienses, dada la audacia que habían demostrado contra el Medo, fueran además dueños de una flota tan considerable (1.90.1). Prevención ante la osadía y la disposición revolucionaria se comprueba en 462 cuando los atenienses que habían acudido a Ítome de Mesenia, en respuesta a la llamada lacedemonia, fueron invitados por estos a retirarse; Tucídides afirma que lo que los había movido a ello eran las sospechas y el temor ante el espíritu

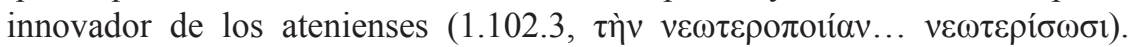
La decisión con la que Atenas estableció inmediatamente alianzas con Argos y Tesalia, justamente regiones medizantes en 480, y, más tarde, ubicó a los hilotas de Ítome en Naupacto (103.3) son reflejo de un cálculo de poder. Nada dice Tucídides de la suerte de Cimón ni de las reformas de Efialtes (Plu. Cim. 15.2-3; 16.9; 17.3). La ruptura con Esparta responde al mecanismo de las 
caracteres nacionales: miedo frente a resolución. Muy poco después, es Corinto la que entra en juego y comete la misma equivocación después de que Megara hubiera sellando una alianza con Atenas. Corinto creyó que era el momento oportuno de derrotar a Megara, pues imaginaba que los atenienses, ocupados en Egipto y Egina (105.1), no podrían hacer nada en su defensa. Pero los corintios sufrieron una grave derrota frente a Mirónides, a la cabeza de los más jóvenes y los veteranos de los atenienses (§ 4-6; cf. Lys. 2.48-52). El lector podrá ver en acción en múltiples ocasiones la hiperactividad y ausencia de miedo atenienses, como cuando en 427 los mitileneos razonaron ante los aliados del Peloponeso que era el momento oportuno para rebelarse porque Atenas, debilitada por la epidemia, con el gasto que conllevaba el envío regular de naves al Peloponeso, y las anuales invasiones de su chôra estaría imposibilitada para reaccionar (3.13.3-4). También en esta ocasión los atenienses procedieron de modo tal que los enemigos concluyeran que habían hecho un mal cálculo: no se movieron de Lesbos, pero equiparon cien naves y las mandaron a las costas del Peloponeso (3.16.1). Así pues, tal vez la tardanza e indecisión del espartiata Álcidas, que debía llegar en apoyo de Mitilene (3.27.1; 30-31), se podría ver como el efecto paralizante que la hiperactividad caracterológica ateniense genera sobre el conservador sistema lacedemonio.

Aunque, para Tucídides, Grecia se había dividido en dos en razón especialmente de la competencia por el liderazgo, en el largo proceso de distanciamiento desempeñaron también un papel las diferencias políticas. Estas se fueron haciendo más evidentes -y más conscientes- desde 462 ${ }^{18}$; y son explotadas durante la guerra (cf. 3.47.2; 82.1). En conclusión, tanto la Arqueología como la Pentecontecia contribuyen a mejorar la comprensión integral de la génesis y desarrollo de la guerra, y desempeñan un papel complementario que es esencial en el relato mismo de los acontecimientos.

\section{Etnias y nómima}

En la primera Arqueología apenas interesa a Tucídides la existencia de grupos étnicos pertenecientes al tronco común heleno, más allá de señalar de dónde y cuándo venían los beocios (1.12.3), qué ciudad es la metrópoli de los jonios (1.12.4) ${ }^{19}$, y en qué momento llegaron los dorios al Peloponeso (los Heráclidas, 1.12.3). Más importan los momentos en que se produce la

\footnotetext{
${ }_{18}$ Y por vez primera se menciona las diferencias étnicas (Th. 1.102.3).

19 Tucídides asume el núcleo histórico del mito de la colonización ateniense de Jonia, un relato que justificaba la existencia del imperio marítimo. Dos regiones se disputaban desde antiguo ser la más antigua tierra Jonia: Acaya y Ática. Eurípides en el Ión fue el primero en eliminar el padre extranjero del héroe y, haciéndolo hijo de Apolo y Creusa, lo convirtió en totalmente ateniense. Cf. Parker 1987: 206-207; Howie 1984: 509.
} 
unidad helena y por qué, finalmente, se dividieron todos los griegos en dos grandes bloques. Por el contrario, en la Arqueología de Sicilia se explicita el origen metropolitano de cada colonia y los nómima instaurados en ellas como consecuencia del mismo ${ }^{20}$. El concepto de nómima está relacionado con el de politeía, e incluye las costumbres religiosas y civiles, las normas consuetudinarias y, también, muchas instituciones sociales y de gobierno. Puede interpretarse que este excurso siciliano, en la lógica del autor, suple el problema de falta de conocimiento sobre las características de la isla que Tucídides achacaba a los atenienses (6.1) y que era la razón por la que realizar esta campaña constituyó un grave error en la dirección de la guerra (cf. Rood 1998: 163).

La pormenorizada clasificación de todos los habitantes sicilianos, mencionados por el historiador en orden cronológico de aparición, y divididos en no-griegos (sicanos, sículos, élimos, fenicios,) y griegos (o, grosso modo, siciliotas $)^{21}$, contribuye a dar la profundidad adecuada al debate asambleario previo a la campaña, en el que Nicias (6.11.1) y Alcibíades (6.17.2-6), sin negar el hecho contrastable de que Sicilia estaba densa y complejamente poblada, difieren en los efectos que el ataque ateniense habría de tener sobre una población muy heterogénea ${ }^{22}$ y todavía sometida a desplazamientos frecuentes a causa de las constantes guerras civiles. Mientras Nicias decía que a Atenas no le iría mal que toda Sicilia cayera en manos de Siracusa porque, argumentaba -sin ningún fundamento-, un imperio no iría nunca a atacar a otro, Alcibíades no tenía en cuenta la posibilidad de que la comunidad cultural y lingüística doria constituyera un argumento emocional para cimentar la unión de los siciliotas dorios con los también dorios del Peloponeso; y confiaba en que muchos sicilianos se aliarían con Atenas. El problema de la unidad o, mejor, de los posibles acuerdos entre los atacantes y algunos locales o, por el contrario, entre todos los griegos de Sicilia frente a los invasores, es lo que pone en conexión la presentación de Tucídides y las distintas maneras en que los dos oradores abordan el asunto de la campaña. A ese aspecto se añadirá, inmediatamente,

${ }^{20}$ De Romilly 1990: 21-27 hace hincapié en la importancia de las relaciones metrópoli colonia ya desde el estallido de la guerra y, muy especialmente, en la segunda parte de la misma. Pero, apunta, Tucídides haría ver al lector que tanto esos vínculos como los étnicos son menos decisivos que los cálculos de interés.

${ }^{21}$ Dover 1953: 14-15 defendió que la fuente de Tucídides para la Arqueología siciliana fue Antíoco y su Sikeliôtis Syngraphé, obra que nuestro historiador empleó e interpretó. La razón, según Dover, para la digresión sería que los atenienses desconocían la obra de Antíoco. Smith 2004 cree que en Atenas circulaban rumores y puntos de vista variados sobre la isla, y reconstruye el estado difuso de conciencia que se había propagado acerca de sus riquezas y la fertilidad de su tierra. Nicolai 2013: 146, 149 considera que las dos Arqueologías son introducciones a las guerras y señala las diferencias. Mientras que la del libro I reconstruye el pasado buscando la línea del poder creciente, la del libro VI presenta el poblamiento siciliano que corresponde a la situación contemporánea.

22 Como indica Rosivach 1987: 302-303, esta heterogeneidad contrastaría con la supuesta homogeneidad ateniense que pone de relieve Alcibíades, y sugeriría falta de lealtad. La falacia reside en que Atenas es una pólis, pero Sicilia no.

Araucaria. Revista Iberoamericana de Filosofia, Política y Humanidades, año 19, nº 37. Primer semestre de 2017. Pp. 235-256. ISSN 1575-6823 e-ISSN 2340-2199 doi: 10.12795/araucaria.2017.i37.12 
el tema de la ruptura de la unidad interna de Atenas. El general siracusano Hermócrates, quien en 425 había conseguido unir a los siciliotas ${ }^{23}$ frente al ataque ateniense $(4.59 .9 ; 60.2 ; 61.1 ; 3 ; 64.3)$, en esta ocasión apeló más a las raíces dorias (6.76.1) de muchos sicilianos y, especialmente, las de la ciudad vecina, de la que Siracusa era metrópoli (1.5.3), y que era su mayor rival, Camarina (6.79.2). Es llamativo que en el catálogo de las fuerzas atenienses, en esta única ocasión, Tucídides haga la diferencia entre jonios, dorios y eolios (7.57.4-6), aunque parece que a lo que concede significación práctica es a los estatus de autónomo, tributario, naval, etcétera, ya que dichas categorías no dependían para nada de la pertenencia étnica.

Por otra parte, que en el texto de esta Arqueología Tucídides especifique en varias ocasiones de dónde toman las leyes las colonias, si son dorias o "calcídicas" (6.4.3; 4.4; 5.1), es significativo ya que establece conexiones entre etnia y nómoi. El historiador ateniense no detalla nunca el funcionamiento institucional de las ciudades pero es consciente de cómo se alineaban los griegos por razones políticas, junto a Esparta o a Atenas. De Esparta dice que desde antiguo, desde la llegada de los dorios, estaba bien ordenada (1.18.1:

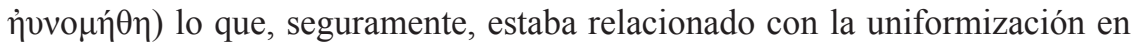
el vestir, índice este de la adopción de un nuevo kósmos igualitario (1.6.4 $)^{24}$. En otra ocasión no deja pasar por alto que los lacedemonios tenían una politeía poco transparente (5.68.2), comentario que no parece muy positivo. $\mathrm{Y}$ nos encontramos con diversas observaciones de autor que son claramente negativas y traducen de qué modos violentos Esparta controlaba la temida desunión interna; por ejemplo, con motivo de la ocupación de Pilos y de la consiguiente conmoción desatada en Esparta, sería autorizada la campaña de Brásidas porque -comenta- de este modo se alejaba de Lacedemonia a una cifra importante de hilotas $(4.79 .3 ; 80.2)$; y ve justificado también contar la anécdota de cómo en una ocasión anterior los espartiatas se deshicieron de dos mil hilotas por temor a las ansias de libertad que estos habían mostrado (4.80.3-4). Más desconcertante aún, si cabe, es la afirmación de que Brásidas era el primer lacedemonio que, fuera de su patria, fue considerado honrado (4.81.3). Nicias, en un último intento de convencer a sus conciudadanos contra la empresa siciliana, identificaba al sistema político oligárquico de Esparta

${ }^{23}$ De Romilly 1967: 28-30 pone de relieve la importancia de esta idea que se apunta en el libro IV y se convierte en hilo conductor desde el VI. Connor 1984: 121 subraya el hecho de que para abonar la idea de unidad de la isla recurra a la expresión oikê̂os pólemos (4.64.5) para referirse a los conflictos que enfrentan a los siciliotas.

${ }^{24}$ El mito reza que Esparta no sufrió la tiranía pero sí las combatió (cf. Hdt. 5.92.1-2). Para las tiranías y la historia de Esparta, Tucídides poseía más información que en los periodos anteriores; además de la local, en primer lugar, Heródoto; cf. Fowler 1996: 62-69. Tucídides (1.6.1-3) menciona también cuándo se abandona en Atenas la costumbre de llevar armas y de vestir los antiguos y lujosos chitônes. Lo primero estaría relacionado con un cese del riesgo de ataques piráticos y lo segundo, con el régimen democrático que los llevaría a adoptar la vestimenta más sencilla doria: cf. Hornblower 1991: 24-25. 
como la verdadera amenaza para Atenas (6.11.7), lo que podría también ser una velada alusión del peligro que suponía la existencia de elementos filolaconios entre los "jóvenes", y un premonitorio e impensado anuncio de la inminente $s t a ́ s i{ }^{25}$. Desde el asunto de Ítome, la conciencia de las diferencias constitucionales debía de haberse ido agudizando, y los primeros diez años de guerra habían contribuido a ello al empezar esta a ser interpretada como un conflicto entre modelos antitéticos de politeíai.

De la democracia de Atenas explícitamente es poco lo que dice Tucídides, ni a favor ni en contra, si excluimos el elogio en la Oración Fúnebre del invierno de 431/30, pero estas son palabras que pronuncia un demócrata, Pericles, y que se adecuan a la circunstancia y protocolo. Igual que Heródoto (5.78.1) cree que el cambio del sistema realizado por Clístenes tuvo efectos directos en los éxitos bélicos de Atenas, Tucídides parece estar convencido de que el carácter ateniense era fruto de la politeía (Sancho Rocher 2011: 171-175) y, por eso, pone de relieve el parecido entre los atenienses jonios y los dorios siracusanos (7.55.2; 8.96.5). Con esto deja meridianamente claro que para él la politeía y/o los nómima tienen mayores consecuencias que la pertenencia a una u otra etnia. Politeía y nómima que, también para Atenas, tendrían un origen remoto y serían la fuente de un determinado modo de ser. En la Arqueología ya comenta que desde bien pronto, los atenienses habían abandonado la perenne militarización por una vida pacífica y confortable (1.6.3), estilo de vida que es el que encomia Pericles en el discurso fúnebre para contrastarlo con el de los enemigos $(2.37 .2 ; 38.1 ; 39.1)$. Seguramente ese condición de 'sociedad abierta' era considerada una peculiaridad tradicional que afectaba a toda el Ática ya que, unificada políticamente desde la época de Teseo $(2.15 .2)^{26}$, la gente vivía, libre de temores y amenazas, dispersa por toda la chôra (cf. 65.2).

Cuando Nicias advirtió sobre el desafío cercano para la democracia no sospechaba los acontecimientos que iban a turbar la paz interna de Atenas. La mutilación de los Hermes parece un acto contra la proyectada campaña; pero también despertó la discordia social. Además, las denuncias paralelas, relativas al escarnio privado de los Misterios, implicaron a Alcibíades (6.28.1; 53.1), y sus enemigos políticos aprovecharon la circunstancia para arrojar sobre él la sospecha genérica de que todo esto - ambos delitos religiosos y otros parecidos cometidos con anterioridad- tenía que ver con un golpe de estado de signo tiránico y oligárquico $(6.53 .2 ; 60.1)^{27}$. Aunque debe de tener razón Tucídides

${ }^{25}$ Alcibíades no solo negó esa eventualidad, sino que cerró la polémica con una emocionada apelación a la colaboración de todos los grupos de edad, en la mejor tradición ateniense, para afrontar la guerra venidera (Thuc. 6.18.6).

${ }^{26} \mathrm{Cf}$. Anderson 2006: 142-143 sobre la reinvención por Clístenes de las fiestas Sinecias. Poner de relieve la unidad política es lo que justificaría el breve excurso del libro II de Tucídides sobre Teseo. Rawlings 1981: 75 dice que Tucídides destaca que durante la primara guerra Atenas aparece como estado unificado.

${ }^{27}$ Cf. Barceló 1990: 414-417 sobre la confusión de ambas realidades; y Rubel 2014: 79-97 contra la existencia de un plan golpista entre los hermocópidas, aunque ve contenido político en el sacrilegio de los Misterios, por su significado identitario y su vínculo con la Liga.

Araucaria. Revista Iberoamericana de Filosofía, Política y Humanidades, año 19, n 37. Primer semestre de 2017. Pp. 235-256. ISSN 1575-6823 e-ISSN 2340-2199 doi: 10.12795/araucaria.2017.i37.12 
cuando sugiere que no existía una trama golpista oligárquica (ni tiránica), eso no significa que la amenaza no resultara verosímil para los oídos del ciudadano común. Tucídides dedicó un amplio paréntesis a narrar cómo, justo un siglo antes, acabó la tiranía en Atenas, y corregir así lo que creía la mayoría ${ }^{28}$. O, dicho de otro modo, lo mal que sabía la mayoría lo ocurrido (6.53.3; 60.1; 1.20.3). Para él no interpretar bien el pasado contribuía a repetir errores parecidos (cf. Smith 2004: 44; Meyer 2008: 26, 29-30). Tucídides censuraba la actuación disgregadora, tanto de los líderes ${ }^{29}$ como del dêmos, en los momentos en los que se requería la unidad. Vio allí el origen de la stásis que se declaró tras la derrota de 413 y que, entonces sí, acabó con la democracia. Su lectura es que el pueblo había sido inducido por algunos demagogos a creer en la existencia, el carácter político y la amplitud de una conjura a la que se hacía responsable de todos los actos irreverentes de 415. Pero los diferentes delitos de impiedad eran infracciones de índole diversa. De ahí el paralelismo con las razones eróticas -y no políticas- del asesinato de Hiparco $(6.54 .1 ; 55.4 ; 59.1)$. No podía esconder, con todo, que entonces hubiera habido alguna conspiración (6.56.2-3; cf. 1.20.2), iniciada por Aristogitón para liberar la ciudad del tirano ${ }^{30}$. La intervención de la oligarquía espartana para expulsar a Hipias era conocida por los atenienses, aunque seguramente la tradición popular al respecto era contradictoria e inconexa. Tucídides estableció el orden y los lapsos de tiempo de los acontecimientos y rebajó la importancia del acto tiranicida - no mataron al tirano: 1.20 .2 ; 6.55-, ocurrido tres años antes de la verdadera expulsión del auténtico tirano, que era Hipias. Evidenció, por otro lado, que oligarquía y tiranía no tenían nada que ver, como se comprobaría en 411. Y apuntó hacia la conclusión de que la rivalidad de los líderes (en el interior) derivó en la fatal (para los intereses externos) desunión de los ciudadanos.

28 "La mayoría" (6.54.2), pero también "otros" (6.54.1) - ¿Helánico?- creían que el asesinado Hiparco era el tirano de Atenas (Schol. An. 10-12 D., [Pl.] Hipp. 228b). Cf. Dover en GommeAndrewes-Dover 1983: 321. Tucídides trató de evidenciar la contradicción entre la leyenda de los tiranicidas y la intervención espartana para expulsar a Hipias.

29 Sobre la responsabilidad de los líderes, cf. Thuc. 2.65.10-11 y 6.28.4. La ausencia de susceptibilidad y sospechas en la democracia $(2.37 .2 ; 3.37 .2)$ se reveló, en esta ocasión, falsa. Meyer 2008: 21 sostiene que en 415, como en 514, eran pocos los conjurados. Comenta Rood 1998: 172173, 178 que Atenas estuvo a punto de lograr la victoria, a pesar de haber retirado a Alcibíades de la dirección, lo que constituyó un auténtico error.

${ }^{30} \mathrm{Si}$ el acto no era político, el objetivo tendría que haber sido Hiparco. Entre otras inconsistencias, Diesner 1959: 540 señala que sabemos por Heródoto que las relaciones de los Pisistrátidas con algunas familias aristocráticas no eran buenas. Rawlings 1981: 103-108 considera esencial en Tucídides el contraste de clases en ambos momentos. Aristogitón sería un mésos y Harmodio un noble

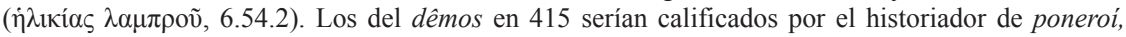
mientras que los acusados, tenidos por hombres honrados y aristócratas. No está claro, sin embargo, que la diferencia que hace el historiador sea exclusivamente social y no, más bien, moral. Loraux 1985: 14 recuerda que los mésoi son, en otros contextos, los responsables de evitar la stásis (3.82.8; 8.75.1; 92.8). Hornblower 2008: 441 señala que el adjetivo lamprós no designa al grupo social al que pertenece Harmodio, sino que modifica el término edad, "en la flor de la edad".

Araucaria. Revista Iberoamericana de Filosofía, Política y Humanidades, año 19, n 37. Primer semestre de 2017. Pp. 235-256. ISSN 1575-6823 e-ISSN 2340-2199 doi: 10.12795/araucaria.2017.i37.12 
Aunque los dos eventos, separados por un siglo, no tienen por qué haber sido construidos en perfecto paralelismo por Tucídides, Alcibíades sí tuvo una actuación parecida a la de Hipias al unirse al enemigo tras su fuga. Así que lo que el dêmos temía antes de la traición de Alcibíades (6.53.3), llegó a ser posible solo cuando, a causa de la paranoia popular de golpe de estado, el pueblo se lanzó, como Hipias, a la persecución y aniquilación de 'sospechosos' que eran inocentes y que reaccionaron como las víctimas de Hipias, con un intento de acabar con el régimen. La desconfianza es sembrada en la vida cívica para destruir la unidad. Igual que los tiranicidas sospecharon erróneamente que habían sido delatados (6.57.2), el dêmos teme de manera infundada la existencia de golpistas y da por buena toda delación (6.53.2-3). El asesinato de Hiparco, calificado de audacia irreflexiva $(6.57 .3 ; 59.1)$, fue una decisión tan precipitada e imprudente como el apartamiento de Alcibíades de la dirección de la guerra en 415. Tucídides, que no concede peso definitivo a la filiación étnica, otorga también valor circunstancial a la forma política ${ }^{31}$. Lo sustancial para la victoria era la cohesión interna y las alianzas que, junto a la buena dirección y los recursos, son la base de todo poder. En 413, con la ayuda de los dorios peloponesios, la ciudad doria de Siracusa, gobernada democráticamente, derrotó en batalla naval a la armada más experimentada, en un momento en el que Atenas estaba dividida. Los atenienses, además, no habían logrado los apoyos esperados entre los enemigos de los siracusanos; habían despreciado el efecto de la numerosa población de la isla y de la solidaridad doria de las metrópolis del Peloponeso. En el invierno de 412/411 se preparaba en la dirección de la democrática escuadra de Samos, a iniciativa de Alcibíades, un golpe de estado que, trasladado a la ciudad, había de acabar con la democracia, y que estuvo a punto de hacer que Atenas fuera definitivamente derrotada. Tucídides no llegó a concluir la redacción de la fase final de la guerra aunque la conocía y eso, con seguridad, condicionó la composición de la Arqueología de Sicilia y del excurso tiránico.

\section{Trópoi y líderes}

La fuerte caracterización con la que Tucídides presenta las dos póleis hegemónicas desde el inicio de la obra es ilustrada al final del libro I a través del modo en el que se producen los prolegómenos de la declaración de guerra. Los lacedemonios exigieron a los atenienses que expiaran "el sacrilegio" (1.126.1) - en alusión al homicidio de los cilonianos en el que estaría implicado

31 Leppin 1999: 171-183 sostiene que para Tucídides el éxito militar es fruto de la politeía, pero no de una específica, democrática u oligárquica, sino de la que cohesiona la polis. 
el arconte epónimo de ese momento, el Alcmeónida Megacles $^{32}$-; y, dice Tucídides, lo hacen porque saben que Pericles era quien más insistía para que sus conciudadanos no cedieran en cuestiones esenciales para la supervivencia del arché. Creían, apunta nuestro historiador, que si este líder era expulsado, a ellos les iría mejor (1.127.1-2), es decir que habría cesiones y no sería necesario ir a la guerra. Hay una aparente contradicción en que el mismo motivo sea a la vez "pretexto" para declarar la guerra y vía para evitar su inicio. Al margen de ello, la respuesta ateniense resulta expeditiva: exigieron, a su vez, a los lacedemonios que expiaran dos sacrilegios, el de Ténaro -el asesinato de varios hilotas que habría desencadenado el terremoto de ca. 465 (128.1)- y el de Atenea Calcíeco ( $\$ 2$ ) -ya que habían tolerado la muerte de Pausanias, el héroe de Platea, en el santuario de la Calcíeco (1.134) - ${ }^{33}$. Si, como dice Tucídides, los espartanos tuvieron siempre mala conciencia por haber iniciado la (primera) guerra, y creían que por ello la fortuna no les había sonreído (7.18.2; a pesar de 4.20.2), no parece que, al menos en ese momento, los atenienses se dejaran impresionar mucho por el hecho de seguir las directrices políticas de un sacrílego Alcmeónida ${ }^{34}$.

Este hecho es la excusa para que el autor encadene, además de la relativa al intento tiránico de Cilón, otras dos breves, ágiles y atractivas digresiones que complementan la idea de que los espartanos eran lentos en sus decisiones y bastante taimados con los extranjeros; que los atenienses, por el contrario, extremaban los correctivos impuestos a sus líderes, pero sin excesiva investigación ni reflexión (cf. Rood 1998: 138). El episodio de Pausanias enlaza con el de Cilón por el tema sacrilegio, el de Temístocles ${ }^{35}$ con el de Pausanias por el tema medismo (Tsakmakis 1995: 139). Pausanias, si creemos a nuestro historiador, fue acusado con razón (1.128.3-131; 95.5) de medismo; además, conspiraba realmente con los hilotas contra el régimen lacedemonio (1.132.4), y trataba a los aliados griegos como un déspota (1.130.2; 95.1). Esto último, reflejo del propio carácter espartano, aceleró el traspaso de la dirección militar que los jonios reclamaron a los atenienses (1.96.1). Los espartiatas se

${ }^{32}$ Cf. Gomme 1971: 427-428 para la fecha, antes de 621, del intento tiránico de Cilón. Tucídides no menciona a Megacles sino "el génos" (1.126.11), es decir la familia de los Alcmeónidas.

33 Rood 2013: 126, 138 destaca el cinismo de la demanda lacedemonia, pero cree que el caso de Cilón (un vencedor olímpico) estaría conectado con el temor ateniense a Alcibíades.

34 Tucídides señala, sin embargo, que los atenienses purificaron Delos (3.104), y este acto podría tener relación con la epidemia sufrida en la ciudad. Los espartanos, aparentemente, eran más susceptibles de sentir ansiedad por razones religiosas, pero no podemos olvidar el juicio de los plateos en 427. Cf. Furley 2006.

${ }^{35}$ Tal vez podría haber prescindido de buena parte de lo narrado en las tres digresiones (Gomme 1971: 446-447), sin embargo su inclusión añade al tratamiento del traspaso de hegemonía el del papel desempeñado por los dirigentes. Sobre el paralelismo de los dos relatos, Konishi 1970 vio el esbozo de dos personajes y sociedades opuestos; Westlake 1977 apuntaba a una fuente escrita que Tucídides habría tomado prácticamente sin variaciones dado el uso de términos infrecuentes en él. El más relevante es el de espartiatas, en lugar del habitual de lacedemonios; Tsakmakis 1995: 117-121 propone fuentes diversas, orales y escritas.

Araucaria. Revista Iberoamericana de Filosofía, Politica y Humanidades, año 19, n 37. Primer semestre de 2017. Pp. 235-256. ISSN 1575-6823 e-ISSN 2340-2199 doi: 10.12795/araucaria.2017.i37.12 
esmeraron en ofrecer pruebas de que lo que se decía de Pausanias tenía alguna base $(132.1 ; 133.1 ; 134.1)$ si bien hoy día nos resulta inverosímil. En el caso de Temístocles, la inculpación de medismo procedía de los lacedemonios (1.135.2), lo que, en principio, tendría que haber inducido a los atenienses a recelar. Sin embargo, dado el funcionamiento del sistema político y judicial de Atenas, dieron por buena la acusación y ordenaron detenerlo en su ostracismo de Argos (1.135.3). Del relato de Tucídides se deduce que Temístocles no previó esta última persecución. De hecho, el contacto con Artajerjes se produjo una vez en Asia (1.137.3), y la carta que dirigió entonces al Rey es prueba de que tuvo que improvisar algún argumento para persuadirlo de que le concediera, junto al asilo, su amistad ${ }^{36}$.

El elogio que Tucídides depara a Temístocles (1.138.3) solo es comparable al que más adelante hace de Pericles (2.65). Mucho es lo que une a los dos grandes hombres que delimitan la pentecontecia ${ }^{37}$. En los dos subraya el historiador especialmente las dotes intelectuales, la capacidad de previsión y la habilidad para transmitir ideas ${ }^{38}$. Solo falta en el primero la insobornabilidad que recalca en el segundo en grado superlativo ( $\alpha \delta \omega \rho o ́ \tau \alpha \tau o \varsigma, 2.65 .8)$. Este rasgo hubiera sido de mucha utilidad en el actual contexto porque disolvería toda duda sobre la inocencia de Temístocles, pero a la vez es muy posible que Tucídides lo haya encontrado inapropiado para alguien que aceptó la donación de tres ciudades por parte del Rey: Magnesia, Lámpsaco y Miunte (1.138. 5). La digresión a que da pie el ultimátum de los lacedemonios se cierra con la apología de Temístocles, complemento de lo que el lector sabe por capítulos previos. Con él Tucídides también introducía la cuestión fundamental de la relación entre líderes y dêmos, y las dificultades de establecer una comunicación racional ${ }^{39}$. Pausanias había hecho asimismo una aparición anterior (1.94-95), por lo que el actual excurso refina el retrato de hombre ambicioso, desleal y corrupto. No solo ve en Pausanias un paradigma lacedemonio -lo demuestra el comentario a contrario que hace de Brásidas (supra)-, Tucídides también contrasta la desfachatez de la reclamación espartana con la claridad con la que Pericles habla a la asamblea.

\footnotetext{
${ }^{36}$ Heródoto recoge el rumor de que el general ateniense habría advertido a Jerjes de que los puentes no habían sido destruidos y de que nada le impediría su huída (8.110.2). Es este el favor que Temístocles recordaría a Artajerjes al escribirle cuando le pidió asilo. Pero lo cierto es que, en un principio, Temístocles había defendido la conveniencia de poner rumbo al Helesponto (108.2). Así que da la impresión de que, como su propuesta fue derrotada y tuvo que convencer a los atenienses de lo contrario (109.2-4), ello dio pie a la calumnia de que estaba dejando huir al enemigo.

37 Dice Connor 1984: 61-62 que el liderazgo era clave para Tucídides, quien piensa que con Pericles al frente Atenas pudo haber ganado la guerra. Temístocles y Pericles tenían clara la relevancia de la flota.

38 Virtudes que también conducen a errores típicos de los atenienses; Cf. Ober 1998: 82: la agudeza

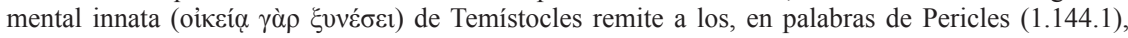

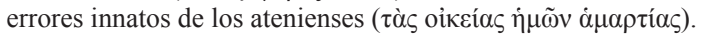

39 Rawlings 1981: 95 afirma que Atenas produce mejores líderes que Esparta pero los trata de manera desastrosa para sus propios intereses.
} 
Al cerrarse el libro I, el lector conoce mejor los antecedentes lejanos y próximos del conflicto y puede abordarlos desde dos puntos de vista complementarios, el estructural y el particular. Atenas entró en guerra estando en posesión de la mayor flota nunca habida, y con recursos ingentes centralizados en la Acrópolis. Los pasos para llegar a este estadio los dieron los atenienses guiados por dos hombres excepcionales, Temístocles y Pericles. Pero, incluso en lo más alto de su gloria, el sistema encerraba también algunos vicios susceptibles de animar la división. Solo cuando la unidad interna de la ciudad empezó claramente a hacer aguas, la alianza del Peloponeso concibió alguna esperanza de quebrar su imperio.

\section{Conclusión}

Las digresiones o excursos tucidídeos cumplen una función muy importante en la economía global de la obra: condensan en momentos señalados y concretos una información muy elaborada que da claves necesarias para la comprensión de la narración general. Tanto las dos Arqueologías como la Pentecontecia son historia selectiva, casi esquelética, pero conscientemente preparada para reforzar la exposición y las conclusiones sobre, en el caso de la primera Arqueología, las bases del poder; en el de la Pentecontecia, la causa más verdadera de la guerra; y, en el de la Arqueología de Sicilia, el fracaso de la expedición. Los recursos económicos, la flota, las alianzas, la unidad interna y una dirección cabal, se revelan como factores de mayor peso que el sistema político o los vínculos étnicos.

Los paréntesis de apariencia más anecdótica, que son más prolijos en los detalles, arrojan luz sobre los comportamientos sociales particulares -los que caracterizan a la democracia de Atenas o a la oligarquía de Esparta- y lo hacen incluso aportando detalles sobre personajes concretos (los tiranos y los tiranicidas, Pausanias y Temístocles), protagonistas de coyunturas históricas determinantes para el presente, bien por la memoria deformada que de los acontecimientos existe, bien por la similitud aparente del pasado y el presente.

La perspectiva temporal que aportan las digresiones permite al autor persuadir a los lectores acerca de las constantes del comportamiento humano, tanto individual como colectivo, conductas a las que no son ajenas nunca las circunstancias del presente y la influencia, en el tiempo largo, de la historia y las tradiciones culturales de cada ciudad. 


\section{Referencias bibliográficas:}

Anderson 2005: G. Anderson, The Athenian Experiment. Building an Imagined Political Community in Ancient Attica, 508-490 BC (Ann Arbor, 2005).

Barceló 1990: P. Barceló, Thukydides und die Tyrannis, "Historia", 39 (1990), pp. 401-425.

Canfora 1982: L. Canfora, Tucidide erodoteo, "QS", 16 (1982), pp. 77-84.

Canfora 2016: L. Canfora, Tucidide. La menzogna, la colpa, l'esilio (RomaBari, 2016).

Cogan 1981: M. Cogan, The Human Thing. The Speeches and Principles of Thucydides' History, (Chicago, 1981).

Connor 1977: W.R. Connor, A Post Modernist Thucydides?, “CJ”, 73 (1977), pp. 289-298.

Connor 1984: W.R. Connor, Thucydides (Princeton, 1984).

Greenwood 2006: E. Greenwood, Thucydides and the Shape of History (Bath, 2006).

Grethlein 2011: J. Grethlein, Historia magistra vitae in Herodotus and Thucydides? The Exemplary Use of the Past and Ancient and Modern Temporalities [in Lianeri 2011], pp. 247-262.

Gribble 1998: D. Gribble, Narrator Interventions in Thucydides, "JHS", 118 (1998), pp. 41-67.

de Romilly 1966: J. de Romilly, Thucydide et l'idée de progres, "ASNP”, 35 (1966), pp. 143-191.

de Romilly 1967: Histoire et raison chez Thucydide (Paris, 1967).

de Romilly 1990: La construction de la vérité chez Thucydides (Paris, 1990).

Diesner 1968: H.J. Diesner, Peisitratidenexkurs und Peisistratidenbild bei Thukydides [in Herter 1968], pp. 531-545 [= "Historia", 8 (1959), pp. 12-22].

Dover 1953: K.J. Dover, La colonizzazione della Sicilia in Tucidide, "Maia", 6 (1953), pp. 1-20.

Dover 1988: K.J. Dover, Thucydides 'as History' and 'as Literature' [in K.J. Dover, The Greeks and their Legacy, Oxford-New York, 1988].

Flory 1990: S. Flory, The Meaning of $\tau \dot{o} \mu v \theta \tilde{\omega} \delta \varepsilon \varsigma$ (1.22.4) and the Usefulness of Thucydides'History, "CJ", 85 (1990), pp. 193-208.

Fowler 1996: R.L. Fowler, Herodotos and his Contemporaries, "JHS", 116 (1996), pp. 62-87.

Furley 2006: W.D. Furley, Thucydides and Religion [in Rengakos Tsakmakis 2006], pp. 415-438.

Gehrke 1993: H.J. Gehrke, Thukydides und die Rekonstruktion des Historischen, "AA", 39 (1993), pp. 1-19. 
Gomme 1971: A.W. Gomme, A Historical Commentary on Thucydides, I: Introduction and Commentary on Book 1 (Oxford, $1971^{5}\left[1945^{1}\right]$ ).

Gomme, Andrewes, Dover 1983: A.W Gomme, A. Andrewes, K.J. Dover, A Historical Commentary on Thucydides, IV: Books V 25-VII (Oxford, $\left.1983^{4}\left[1970^{1}\right]\right)$.

Herter 1968: H. Herter, ed.: Thukydides (WdF 98) (Darmstadt, 1968).

Hornblower 1991: S. Hornblower, A Commentary on Thucydides, I: Books I-III (Oxford, 1991).

Hornblower 2008: S. Hornblower, A Commentary on Thucydides, III: Books 5.25-8.109 (Oxford, New York, 2008).

Howie 1984: G. Howie, Thukydides' Einstellung zur Vergangenheit. Zuhörerschaft und Wiesenschaft in der Archäeologie, "Klio", 66 (1984), pp. 502-532.

Hunter 1980: V. Hunter, Thucydides and the Uses of the Past, "Klio" 62, (1980), pp. 191-218.

Hunter 1982: V. Hunter, Past and Present in Herodotus and Thucydides (Princeton, 1982).

Johnson 1993: L.M. Johnson, Thucydides, Hobbes, and the Interpretation of Realism (Dekalb, 1993).

Konishi 1970: H. Konishi, Thucydides' Method in the Episodes of Pausanias and Themistocles, "AJPh", 91 (1970), pp. 52-69.

Kurz 1970: D. Kurz, AKPIBEIA. Das Ideal der Exaktheit bei den Griechen bis Aristoteles, (Göppingen, 1970).

Leppin 1999: H. Leppin, Thukydides und die Verfassung der Polis. Ein Beitrag zur politischen Ideengeschichte des 5. Jahrhunderts v. Chr. (Berlin, 1999).

Lianeri 2011: A. Lianeri, ed.: The Western Time of Ancient History. Historiography Encounters with the Greek and Roman Parts (Cambridge, 2011).

Loraux 1985: N. Loraux, Enquête sur la construction d'un meurtre en histoire, “L'écrit du temps", 10 (1985), pp. 3-21.

Luraghi 1995: N. Luraghi, La tirannide siciliota nell' "Archaiologia” di Tucidide, "QS", 42 (1995), pp. 35-63.

Meyer 2008: E.A. Meyer, Thukydides on Harmodius and Aristogiton, Tyranny and History", "CQ",58 (2008), pp. 13-34.

Müri 1968: W. Müri, Beitrag zum Verständnis des Thukydides, in [Herter 1968], pp. 251-275 [= “MH”, 4 (1947)].

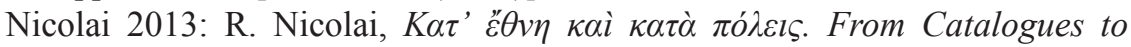
Archaeology [in Tsakmakis, Tamiolaki 2013], pp. 139-151.

Ober 1998: J. Ober, Political Dissent in Democratic Athens. Intellectual Critics of Popular Rule (Princeton, NJ, 1998). 
Parker 1987: R. Parker, Myths of Early Athens [in J. Bremmer, ed.: Interpretations of Greek Mythology, London, 1987], pp. 187-214.

Raaflaub, K., 2013, Ktema es aiei: Thucydides' Concept of Learning through History [in Tsakmakis, Tamiolaki 2013], pp. 3-21.

Rawlings 1981: H.R. Rawlings III, The Structure of Thucydides History (Princeton, NJ, 1981).

Rengakos, Tsakmakis 2006: A. Rengakos, A. Tsakmakis, eds.: Brill's Companion to Thucydides (Leiden, 2006).

Rood 1998: T. Rood, Thucydides Narrative and Explanation (Oxford, 1998).

Rood 1999: T. Rood, Thucydides'Persian Wars [in Ch. Shuttleworth, ed.: The

Limits of Historiography: Genre and Narrative in Ancient Historical Text,

Leiden, Boston, Köln], pp. 141-168.

Rood 2006: T. Rood, Objectivity and Authority: Thucydides' Historical Method [in Rengakos, Tsakmakis 2006], pp. 225-249.

Rood 2013: T. Rood, The Cylon Conspiracy: Thucydides and the Uses of the Past [in Tsakmakis, Tamiolakis 2013], pp. 119-138.

Rosivach 1987: V. Rosivach, Autochthony and the Athenians, "CQ”, 37 (1987), pp. 294-306.

Sancho Rocher 2011: L. Sancho Rocher, Arché y democracia a la luz de Tucídides [in J.M. Cortés Copete, E. Muñiz Grijalvo, R. Gordillo Hervás, eds.: Grecia ante los imperios, Sevilla, 2011], pp. 167-177.

Smith 2004: D.G. Smith, Thucydides'Ignorant Athenians and the Drama of the Sicilian Expedition, "SyllClass", 15 (2004), pp. 33-70.

Stadter 1993: Ph.A. Stadter, The Form and Content of Thucydides' Pentecontaetia (1.89-117), "GRBS", 34 (1993), pp. 35-72.

Stahl 1966: H.P. Stahl, Thukydides. Die Stellung des Menschen in geschichtlichen Prozeß (München, 1966).

Thomas 2011: R. Thomas, Thucydides and Social Change: Between akribeia and Universality [Lianeri 2011], pp. 233-245.

Trédé 1983: M. Trédé, Akribeia chez Thucydide [in Mélanges offerts à E. Delebecque, Publications de l'Université de Provence, Marseille, 1983], pp. 403-415.

Tsakmakis 1995: A. Tsakmakis, Thukydides über die Vergangenheit (Tübingen, 1995).

Tsakmakis, Tamiolaki 2013: A. Tsakmakis, M. Tamiolaki, eds.: Thucydides between History and Literature (Berlin-Boston, 2013).

Wecowski 2013: M. Wecowski, In the Shadow of Pericles: Athens's Samian Victory and the Organisation of the Pentekontaetia in Thucydides" [in Tsakmakis, Tamiolakis 2013], pp. 153-166.

Westlake 1977: H.D. Westlake, Thucydides on Pausanias and Themistocles -A Written Source?, "CQ”, 27 (1977), pp. 95-110. 